\title{
Notched sign and bamboo-joint-like appearance in duodenal Crohn's disease
}

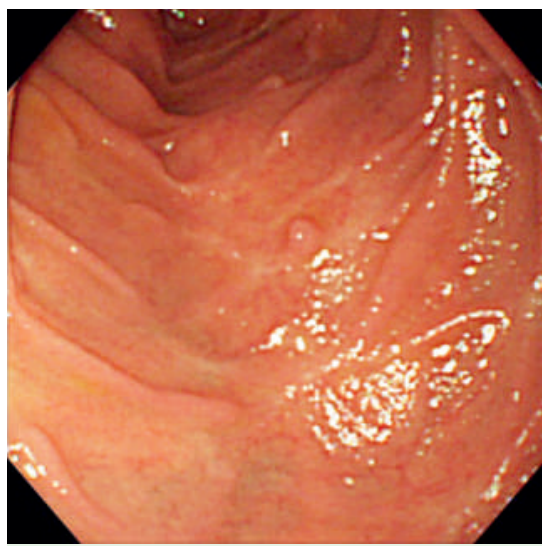

Fig. 1 Endoscopic view of notches in Kerckring's folds of the descending duodenum.

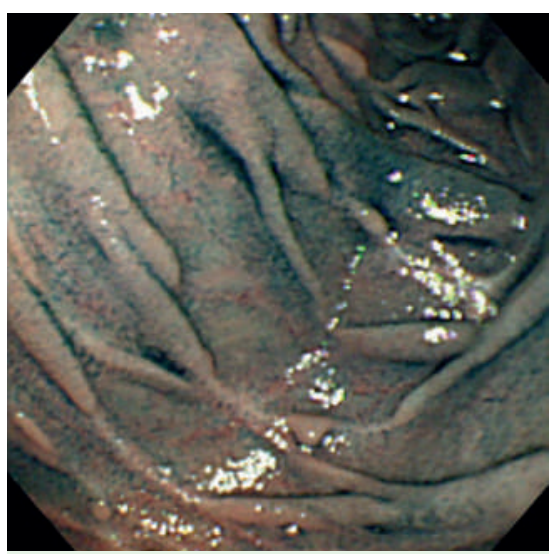

Fig. 2 Ulcer scars with pseudopolyps in a longitudinal skip pattern were identified by spraying with indigo carmine dye.

Although Crohn's disease can affect any part of the gastrointestinal tract, the most common lesions are located in the ileum and the colon; gastroduodenal lesions have therefore attracted less attention. We describe a case of Crohn's disease with characteristic duodenal manifestations.

A 30-year-old man with a 2-year history of Crohn's disease was referred to our institution because of recurrent bowel obstruction due to ileal strictures. At presentation, he was asymptomatic. Physical examination and routine laboratory values were unremarkable. Upper gastrointestinal endoscopy for preoperative evaluation showed notches in the Kerckring's folds of the descending duodenum ( Fig. 1). Closer observation using indi-

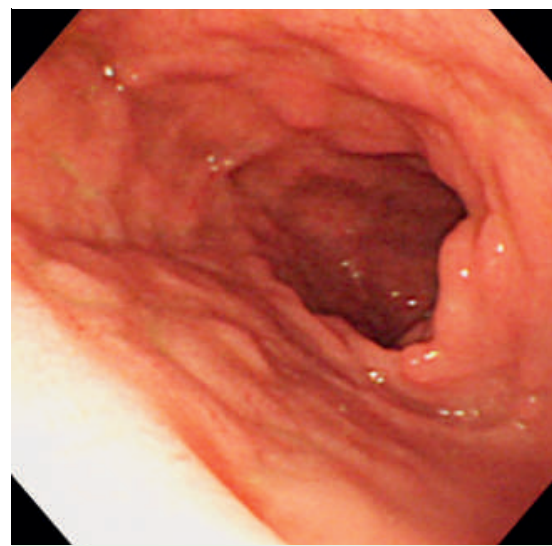

Fig. 3 Endoscopic view of nodular mucosa of the duodenal bulb.

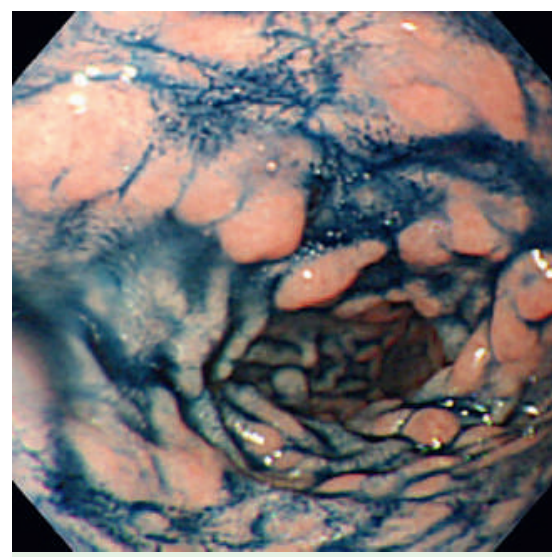

Fig. 4 A longitudinal fold with bamboo-jointlike appearance was evident.

go carmine dye revealed ulcer scars with pseudopolyps presented in a longitudinal skip pattern ( $\mathbf{F i g . 2}$ ). In the duodenal bulb, nodular mucosa was present (๑ Fig. 3). A longitudinal fold with a bamboo-joint-like appearance was evident ( $\bullet$ Fig. 4). The patient underwent scheduled ileocecal resection with an uneventful recovery.

The endoscopic and radiological features of gastroduodenal Crohn's disease are similar to those of more distal disease, featuring irregular mucosal thickening, nodular (cobblestone) mucosa, aphthous ulcers, linear ulcers, and duodenal strictures [1,2]. Among various findings, notches in the Kerckring's folds, as shown in our case, are pathognomonic of duodenal Crohn's disease [3]. More recently, better diagnostic procedures have led to a higher rate of detection of gastroduodenal Crohn's disease. A bamboo-joint-like appearance along the lesser curvature of the gastric cardia, characterized by swollen longitudinal folds traversed by erosive fissures or linear furrows, has been regarded as a specific feature of gastric Crohn's disease and can be found in half of patients if examined carefully using dyes [4]. Our case illustrates the possibility that a bamboo-joint-like appearance may serve as an additional pathognomonic marker of duodenal Crohn's disease. The above specific gastroduodenal findings are likely to be implicated in active and extensive Crohn's disease [5].

Endoscopy_UCTN_Code_CCL_1AB_2AZ_3AC

\section{A. Hokama, M. Nakamura, Y. Ihama, H. Chinen, K. Kishimoto, F. Kinjo, J. Fujita}

First Department of Internal Medicine, University of the Ryukyus, Okinawa, Japan

\section{References}

1 Rutgeerts $P$, Onette E, Vantrappen $G$ et al. Crohn's disease of the stomach and duodenum: a clinical study with emphasis on the value of endoscopy and endoscopic biopsies. Endoscopy 1980; 12: 288-294

2 Nugent FW, Roy MA. Duodenal Crohn's disease: an analysis of 89 cases. Am J Gastroenterol 1989; 84: 249-254

3 Cameron DJ. Upper and lower gastrointestinal endoscopy in children and adolescents with Crohn's disease: a prospective study. J Gastroenterol Hepatol 1991; 6: 355-358

4 Yokota K, Saito Y, Einami K et al. A bamboo joint-like appearance of the gastric body and cardia: possible association with Crohn's disease. Gastrointest Endosc 1997; 46: $268-272$

5 Kuriyama M, Kato J, Morimoto Net al. Specific gastroduodenoscopic findings in Crohn's disease: comparison with findings in patients with ulcerative colitis and gastroesophageal reflux disease. Dig Liver Dis, DOI: 10.1016/j.dld.2008.01.008

Bibliography

DOI 10.1055/s-2007-995774

Endoscopy 2008; 40: E151

(c) Georg Thieme Verlag KG Stuttgart · New York ISSN 0013-726X

\section{Corresponding author}

\section{A. Hokama, MD}

First Department of Internal Medicine University of the Ryukyus

207 Uehara

Nishihara

Okinawa 903-0215

Japan

Fax: +81-98-8951414

hokama-a@med.u-ryukyu.ac.jp 